produce a given function. As this multidisciplinary field grew, practitioners envisaged bolder applications, such as building collections of interchangeable parts and devices, and transforming microorganisms into factories for biofuels or drugs.

Bringing these applications to reality has proved much harder than was originally hoped (see page 288). But the difficulties have proved instructive. Indeed, the decade-old papers raised several new and fundamental issues in biology, for example by pointing to the crucial role of noise in gene expression, both as a nuisance and as a great computational opportunity. It is now an active area of research.

More importantly, the difficulties encountered when building such basic circuits announced the demise of intuition as a reliable guide to biological understanding. It took endeavours in synthetic biology to illustrate what systems biology perhaps should mean: to enlist mathematical formalism in producing biological insights that are beyond the reach of mere intuition. In that aspect, synthetic and systems biology now seem indissociable, a theme illustrated by the selection of 'synthetic systems biology' papers published in Nature over the past ten years, and gathered in this week's web focus (http://go.nature.com/Dq38zq).
Undoubtedly some strands of synthetic biology are media friendly and run the risk of hype. But it is not an overstatement to say that the potential of synthetic biology remains enormous: clean and sustainable biofuels, cheap drug production and synthetic organs are just a few of the applications that have been advanced, albeit through small, painfully incremental steps, in the past decade. Full realization of such elating prospects demands patience as well as the efforts and ingenuity of a rich diversity of biologists, physicists, chemists, mathematicians and engineers.

New gadgets will not be the only outcome. One goal of synthetic biology is to synthesize larger and more complex biological systems, as exemplified by the quorum of genetic clocks displayed by Tal Danino et al. in this issue (see page 326). As it develops along this and other paths, synthetic biology itself will demand more by way of new fundamental biological knowledge - quantitative, systematic, computational and biophysical. And conversely, one of the deepest lessons from these first ten years is that biological knowledge will require synthetic approaches if it is to become a mature and reasonably predictive science.

\section{Self-inflicted damage}

\section{The autocratic actions of an institute's founder could destroy a centre of excellence for brain research.}

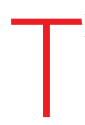

he 2002 launch of the European Brain Research Institute (EBRI) in Rome was a joyous occasion. Spearheaded by Italy's Rita Levi-Montalcini, a Nobel laureate, the EBRI was intended to be a haven from the bureaucracy and cronyism that suffocates Italy's public research system. It would operate solely on the basis of research excellence, not the administrators' personal interests, and appointments would not be for life. It would be a unique opportunity to create an institution of truly international stature in Italy.

Enthused by that prospect, high-ranking scientists from across Europe agreed to join the EBRI's board of directors. Its International Science Council includes no fewer than three Nobel laureates. And with the guidance of these groups, the EBRI has blossomed.

But now the institute may be disintegrating. The EBRI has always had to scratch around for funding, but a spectacular and potentially lethal blow has just been delivered by Levi-Montalcini herself.

Levi-Montalcini, who will be 101 this year, is the EBRI's president. In November, she began unilateral procedures to sack the EBRI's board of directors and to substitute a commissioner, whom she would appoint.

The move has left board members aghast and angry. They say that it is actually against the EBRI's own by-laws. Certainly the formal and informal reasons Levi-Montalcini has given for her action are unconvincing. For example, she maintains that foreign board members could not be expected to follow important discussions or documents in Italian. But international scientific institutions routinely conduct their high-level business meetings in English, the international language of science, and translate documents as necessary.

Levi-Montalcini has also referred to board members' supposed unreliability when it comes to attending meetings - a charge that has caused deep offence among hard-working and enthusiastic members who say that they have had to rise before dawn on many occasions to join meetings called at short notice.

There has been one clear-cut dispute with a board member: Luigi Amadio, the director of the Santa Lucia Foundation, which owns the building in which the EBRI is housed on a rent-free basis. Amadio cut off amenities to EBRI scientists in a dispute over alleged late payment of bills last year (see Nature doi:10.1038/news.2009.888; 2009). But this argument hardly applies to the whole board.

Whatever Levi-Montalcini's motivation, if her changes to the EBRI's governance go through, as seems likely, then the international loss of goodwill towards the institute may be irreversible. The outraged science council members are already discussing possible resignation.

The demise of the EBRI would be a huge disappointment for the talented young researchers who work there, one of whom recently won a highly prestigious grant from the European Research Council. It would also be disappointing for Italy, whose none-too-good scientific image can do without being sullied further. And it would be a tragedy for the much-loved and much-respected Levi-Montalcini herself, who has done so much for sci-
"If the changes go through, the international loss of goodwill towards the institute may be irreversible." ence in her long life (see Nature 458, 564-567; 2009), and who now risks losing the goodwill of some of the world's best neuroscientists who have supported her.

The only remaining hope is that the Prefect of Rome, the local official who must approve the change, will reject her arguments. Levi-Montalcini needs to allow the board of directors to continue meeting and to sort out with those directors whatever concerns she has in a formal and open way. She would be better served by heeding advice from this board than by acting on the impulses that are moving her now. 


\section{Correction}

The Editorial 'Self-inflicted damage' (Nature

463, 270; 2010) incorrectly stated that Rita Levi-

Montalcini intends to appoint a new commissioner

at the European Brain Research Institute in Rome.

In fact, if her plans go ahead, the appointment

would be made by the local prefecture. In addition,

the Editorial spoke of Italy's "none-too-good

scientific image". This was meant to refer to the

nation's image problem in terms of reliability as a

scientific partner; it was not intended to call into

question Italy's scientific skills and ability. 